\title{
Study on the Countermeasures of Improving Part-Time Employment In China
}

\author{
Hong-Zhen LIN ${ }^{1 a^{*}}$, Yu WANG ${ }^{2 b}$ \\ ${ }^{1}$ School of Management, Wuhan University of Science and Technology Wuhan, China \\ Distinct addresses: 947 He Ping Street, Hubei Wuhan 430081, China \\ linjingziran@126.com \\ ${ }^{2}$ School of Management, Wuhan University of Science and Technology Wuhan, China Distinct \\ addresses: 947 He Ping Street, Hubei Wuhan 430081, China \\ 1069189110@qq.com
}

\begin{abstract}
Key words: Part-Time Employment, Flexibility, Multiplicity
\end{abstract}
\begin{abstract}
The purpose of this paper is to research Part-time employment. Using the method of investigation and document study obtain related data in order to correctly, deeply understand the Part-time employment problem. Part-time employment is a form of flexible employment, which is the result of the rapid development of China's market economy, the constant adjustment of industrial structure and economic structure. Its low labor cost and flexible working hours make it more and more popular with workers and workers in the increasingly serious employment situation. the lack of specific legislation on part-time employment, causes many problems in practice, legitimate rights and interests of part-time workers violating the situation is more prominent. The conclusion is that some reasonable suggestions and Effective measures should be put forward to promote and perfect Part-time employment.
\end{abstract}

\section{Introduction}

Part-time labor refers to the normal working hours less than comparable full-time normal working hours. An employment form establish labor relations with a number of employers. Part-time employment is a product of social and economic development to a certain historical stage. In 1970s, many countries and regions entered the era of industrial restructuring, and the restructuring of the economy promoted the development of non-industrialized economy, and the three industries, such as service industries, had risen rapidly. Service industry has the irregularity and discontinuity which is different from manufacturing industry. The characteristics of this industry structure bring deep influence to the global labor market. The most obvious is the labor form change, new ways of employment are highly flexible and elastic characteristics have developed, part-time employment development is developing rapidly in that environment.

The legal system always lags behind social practice. China's current labor contract law on part-time labor regulations lacks of operability. The good legislative mode should help to effectively protect the legitimate rights and interests of part-time workers. Expansion of the fraudulent "identity difference", unreasonable condition treatment, low labor remuneration, unpaid labor security and a series of problems, not only lead to part-time workers into survival predicament, it is worrying, but also further intensified the contradiction between the employer and the employee $^{[1]}$. It is not conducive to building a harmonious society in china. Thus, on the basis of China's national conditions, it is of great significance to further improve the part-time labor legislation and strengthen the protection of the rights and interests of workers. 


\section{Features of Part-Time Employment}

\section{First of All, Temporary Labor Relations}

Part-time employment refers to the hour workers less than four hours in the same employer the average daily working hours, working hours per week for a total of not more than twenty-four hours of labor form. From this definition we can see that part-time workers do not need all day long stay in a employer, so workers can be assigned their own labor free use, that is to establish labor relations with a number of employers [2]. This approach weakens the subordination of workers to employers, which fundamentally creates the flexibility of this kind of employment. This flexibility allows the two-way choice of employers and workers to be freer.

\section{Secondly, The Multiplicity of Labor Relations}

With the development of market economy in China, the employment market is becoming more and more mature, and many employment patterns and various forms of labor have developed rapidly. The personal attributes and organizational attributes are gradually weakened, which leads to the loosening of the link between the laborers and the employers. It has become a new trend to establish labor relations with many employers, to provide labor for multiple employers and to obtain more labor remuneration.

\section{Thirdly, Non Standardization of Labor Relations}

Under the background of economic globalization, flexible allocation of labor force has become an effective way to reduce labor costs and increase the competitiveness of enterprises. Non full-time labor and labor relations are weak, mostly short-term and temporary, while labor relations between traditional labor relations are close and long-term. The flexible features of nonstandard employment have been developed rapidly because of meeting the needs of market economy and flexible allocation of labor force [3].Labor relations are becoming more and more nonstandard all over the world. The value of labor contract will be re recognized, and the connotation of personal attachment is changing. It can be said that non-standard labor relations has become a world trend.

\section{Problems of Part-Time Employment}

\section{First of All, Oral Labor Contract Form is not Helpful to the Protection of the Rights and Interests of Workers.}

The labor contract between employees and employers on the establishment, alteration and termination of labor rights and obligations of the agreement, also called labor contract, the general civil contract can be in the form of an oral or written form, but because the labor contract relationship to establish labor relations, with the nature of social law, China's" labor law and the" labor contract law "the form of doctrine, the establishment of full-time labor relations must sign a written labor contract. However, part-time employment is a flexible mode of employment, and the law requires different forms of its labor contract [4]. In order to better maintain the form of part-time employment flexibility to promote employment, labor contract law adopts the most relaxed mode, which is not compulsory written labor contract between servant unit and the laborers.

Labor relations between the two parties can enter into an oral agreement, which means that both parties can make choice in the oral agreement and written agreement. Especially in the contradiction between labor supply and demand in China is significant, "strong capital weak labor" pattern, the weak position of workers, and part-time employment in the labor contract period is short and the flow of laborers is strong. When the worker and the employer dispute in the contract, how the burden of proof is essential. Written labor contract is undoubtedly the most favorable evidence to protect workers [5]. The labor contract law does not require employers to sign written labor contracts, which is obviously not conducive to the protection of the rights of workers. 


\section{Secondly, Part-Time Work Hours and Vacations Are Not Guaranteed.}

Part-time workers work overtime as a serious problem. At present, the part-time employment in our country mainly focus on community service, fast food and other industries [6]. The characteristics of these jobs easily prolong labor time. The current labor laws and regulations in our country do not regulate the overtime work of part-time labor, and the regulation of full-time labor cannot play a role in part-time employment. Therefore, in the presence of part-time employment with the case, some workers scope and conditions, procedures, extended degree, the legal effect and the lack of legal provisions, provide an effective way for legislation.

Part-time workers are not entitled to leave. For full-time employment of workers in China, they are mostly engaged in short-term labor, at the same time are most likely not work for a year, and often change units, and part-time workers are paid by the hour. In this case, the relevant personnel of part-time workers and accumulated management difficulties. Time cannot be effective statistics they accumulated work, so part-time workers cannot enjoy the holidays and family leave benefits. The employer can save the cost of human resources of the purpose, when the holidays, family leave, pregnant female workers [7]. The part-time workers can not enjoy the right to leave. Therefore, the existing labor laws and regulations on the leave of the corresponding provisions, for part-time workers, they basically cannot enjoy.

\section{Measures to Promote Part-Time Employment}

\section{First of All, Part Time Employment Contract Shall Be In Written Form.}

Allowing oral contracts is not conducive to defining the rights and obligations of both parties in part-time employment. Because legal consciousness of citizens is relatively weak and the labor legislation is incomplete, the collective contract becomes a mere formality and the labor market credit is low. Most of the rights and obligations of part-time workers need to be determined through labor contracts [8]. The oral contract compliance and performance depends on the widely established in the sense of good faith, but it is lack of both parties. Ultimately, it may influence the steady development of part-time employment in our country and even undermine the social harmony and stability.

In Written form, the rights and obligations of both parties clear, as evidence in the event of a dispute, to court, solve the dispute between the parties, but also facilitate the relevant departments to monitor the employment situation of the employer. In written form, the labor cost for the employer's influence is very small, and will not affect the part-time employment flexibility because part-time employment flexibility is mainly the working time, place and method of flexible, to sign a written labor contract will not be affected.

\section{Secondly, Improving the Working Hours and Holidays for Part-Time Workers.}

Labor law is a kind of law of public and private combination. Its regulation of labor standard reflects the nature of a public law. The public nature of the intervention, should be the basic rights and interests of workers by the bottom line protection, to reflect the actual working hours system, the life and health of workers power line protection, reflected on the long working time limit. Daily and weekly full-time workers in all the long hours unit in our country, need for the upper limit on the basis of the existing provisions on the ceiling to standard working hours for full-time employment as a reference, namely part-time workers.

The right to leave is essentially a right of life and health, and a basic human right for workers. In order to protect the life and health of workers, labor time and labor intensity must be limited. When supplementary provisions are made for the vacation of part-time employment in China, we can make proper adaptations to the conditions for part-time workers to enjoy holidays so as to meet the needs of short-term and regular changes in part-time labor [9]. In terms of annual paid vacation, when the part-time workers reached a limit in the same unit accumulative working time can enjoy 
annual leave, but non full-time workers enjoy the vacation days, should be in accordance with its working hours. Perfecting the part-time employment of workers can encourage more vacation, long time in the post improvement of part-time employment leave degree and can promote more workers in the post for a long time. weakening the part-time employment of short-term and frequent changes in the adverse effects, and regulate and promote the short-term and part-time employment the frequent changes of the adverse effects to promote the development of standardized part-time workers.

\section{Conclusion}

Part-time employment is a typical flexible employment model, which has greatly promoted the employment and economic development of our country, and this role will become more and more obvious. At the same time, the development of part-time labor also poses a great challenge to China's labor legislation. This requires us to correctly choose the value system of part-time employment, and produce essential attribute, the part-time employment relationship in flexible employment in our country has developed and non-standard labor in interpretation. We need to reshape the value concept of part-time employment and fully analyze the attributes of nonstandard employment on the basis of knowing that it is a kind of labor and employment. This requires us to adhere to the low level, wide coverage and protection of part-time employment, limited release according to the rigid provisions of its existing legal part-time employment from the property and characteristics of labor flexibility weakened. The legal regulation of part-time employment, we should strengthen the protection of part-time workers, to assume more employer obligations, correction of essence of the labor relationship between the two parties unequal relationship, to ensure the fairness of the bottom line. On this basis, we pay more attention to allow employers and workers to follow free consultation and choice on base of the market rules.

\section{Acknowledgement}

This research was financially supported by Project Hubei Province Education Department Foundation: Study on legal guarantee for flexible employment of workers in excess capacity industry in Hubei Province. No. $17 Y 016$

\section{References}

[1] Li Kungang, Qiao Anli. Study on the perfection of part-time employment system in China [J]. Chinese Jianghuai forum, 2015 (3): 88-95.

[2] Zhao Zhao, Zhang Zhaodong. Study on the problem of part-time labor overtime [J]. China labour, 2017 (3): 36-40.

[3] Zhu Jie, Zhu Xudong. Legal problems and solutions of part-time employment [J]. management and management, 2016 (5): 21-22.

[4] Ma Yang. Employee rights protection in overtime employment. [J]. Great Eastern, 2016 (5): 298-299.

[5] Liu Yelin. Who's on the job? [J]. union information, 2016 (34): 18-19.

[6] Zhang Qian. Non full-time employees should enjoy the benefits of industrial injury insurance [J]. world of labor and security, 2015 (34): 47-47.

[7] Sun Zhaokun. The pros and cons of enterprise part-time labor management [J]. human resources development, 2015 (8): 87-87.

[8] Lin Zhaofei, Tu Qiu Hua. The defects and perfection of the part-time labor relation in China [J]. 
Journal of Harbin University, 2015, 36 (3): 56-59.

[9] Xu Xiaoxiang. Study on the perfection of part-time employment system in China [J]. Journal of legal system and society, 2015 (28): 88-95. 